\title{
IMPACT OF HUMAN PLATELET LYSATE ON THE EXPANSION AND CHONDROGENIC CAPACITY OF CULTURED HUMAN CHONDROCYTES FOR CARTILAGE CELL THERAPY
}

\author{
J.G. Sykes, J.H. Kuiper, J.B. Richardson ${ }^{\dagger}$, S. Roberts, K.T. Wright and N.J. Kuiper* \\ Institute of Science and Technology in Medicine (ISTM), University of Keele, Arthritis Research Centre, \\ The Robert Jones and Agnes Hunt Orthopaedic Hospital, Oswestry, UK \\ ${ }^{+}$Deceased
}

\begin{abstract}
High hopes have been pinned on regenerative medicine strategies in order to prevent the progression of cartilage damage to osteoarthritis, particularly by autologous chondrocyte implantation (ACI). The loss of chondrocyte phenotype during in vitro monolayer expansion, a necessary step to obtain sufficient cell numbers, may be a key limitation in ACI. In this study, it was determined whether a shorter monolayer expansion approach could improve chondrogenic differentiation. The effects of two supplement types, foetal bovine serum (FBS) and Stemulate ${ }^{\mathrm{TM}}$ (a commercial source of human platelet lysate), on the expansion and re-differentiation potential of human chondrocytes, isolated from five individuals, were compared. Chondrocytes were expanded with $10 \%$ FBS or $10 \%$ Stemulate $^{\mathrm{TM}}$. Pellets were cultured for $28 \mathrm{~d}$ in chondrogenic differentiation medium and assessed for the presence of cartilage matrix molecules and genes associated with chondrogenicity. Stemulate ${ }^{\mathrm{TM}}$ significantly enhanced the proliferation rate [average population doubling times: FBS, $25.07 \pm 6.98 \mathrm{~d}$ (standard error of the mean, SEM) vs. Stemulate $\left.{ }^{\mathrm{TM}}, 13.10 \pm 2.57 \mathrm{~d}(\mathrm{SEM})\right]$. Sulphated glycosaminoglycans (sGAG), total collagen and qRT-PCR analyses of cartilage genes showed that FBS-expanded chondrocytes demonstrated significantly better chondrogenic capacity than Stemulate ${ }^{\mathrm{TM}_{-}}$ expanded chondrocytes. Histologically, FBS-expanded chondrocyte pellets appeared to be more stable, with a more intense staining for toluidine blue, indicating a greater chondrogenic capacity. Although Stemulate ${ }^{\mathrm{TM}}$ positively influenced chondrocyte proliferation, it had a negative effect on chondrogenic differentiation potential. This suggested that, in the treatment of cartilage defects, Stemulate ${ }^{\mathrm{TM}}$ might not be the ideal supplement for expanding chondrocytes (which maintained a chondrocyte phenotype) and, hence, for cell therapies (including ACI).
\end{abstract}

Keywords: Human platelet lysate, Stemulate ${ }^{\mathrm{TM}}$, foetal bovine serum, human chondrocytes, cartilage, autologous chondrocyte implantation.

*Address for correspondence: Dr Nicola J. Kuiper, Institute of Science and Technology in Medicine (ISTM), University of Keele, Arthritis Research Centre, The Robert Jones \& Agnes Hunt Orthopaedic Hospital, Oswestry, Shropshire, SY10 7AG, UK.

Telephone number: +44 1691404451 Email: n.j.kuiper@keele.ac.uk

Copyright policy: This article is distributed in accordance with Creative Commons Attribution Licence (http://creativecommons.org/licenses/by-sa/4.0/).

\section{Introduction}

Damaged articular cartilage has a limited potential for healing and untreated cartilage defects often progress to osteoarthritis (OA) (Davies-Tuck et al., 2008). Regenerative medicine strategies have been formulated to meet the challenge of preventing progression to OA; one such strategy is autologous chondrocyte implantation (ACI) (Nawaz et al., 2014). ACI has evolved over 20 years, but chondrocytes are still the preferred cell choice. In brief, autologous chondrocytes are harvested by arthroscopy from a lesser weight-bearing area of the joint, expanded in monolayer culture and re-implanted into the damaged area under a natural or synthetic membrane by an open joint surgical procedure (Brittberg et al., 1994). Robert Jones \& Agnes Hunt (RJAH) Hospital, Oswestry and others report a high percentage of good to excellent clinical results (Bhosale et al., 2009; Henderson et al., 2003). Although there is limited long-term follow-up data, especially from the modern methods of ACI, positive clinical results are beginning to emerge. Nawaz et al. (2014) report a $78 \%$ at 5 years and $51 \%$ at 10 years ACI graft survival 
for 827 patients. A robust economic model, based on a systematic review, indicates that ACI is costeffective as compared with alternative procedures, providing long-lasting improvements in symptoms and eventually reducing the need for knee joint replacements (Mistry et al., 2017; Web Ref. 1). Overall, the consensus is that ACI is more effective if used early following a cartilage injury and if it is the first attempt at a surgical intervention. Further refinement of ACI will ultimately enhance clinical outcomes and this, in part, is one of the goals of the present study.

To obtain sufficient cell numbers from small cartilage biopsies, the chondrocytes need to undergo in vitro expansion. The loss of chondrocyte phenotype, known as de-differentiation (Benya and Shaffer, 1982; Schnabel et al., 2002), during in vitro expansion on tissue culture plastic is a key limitation of ACI. During de-differentiation, chondrocytes lose their rounded morphology and decrease gene and protein expression of collagen II and aggrecan, both key components of the articular cartilage extracellular matrix (ECM). Consequently, de-differentiation decreases the capacity of re-implanted chondrocytes to regenerate functional cartilage (Schulze-Tanzil, 2009). At the RJAH Hospital, Oswestry, most of the freshly isolated chondrocytes usually undergo two passages because de-differentiation is known to occur in as few as three passages (Kang et al., 2007). Nevertheless, further minimising the conditions that promote chondrocyte de-differentiation may improve ACI.

Current standard protocols for chondrocyte expansion involve growth medium supplemented with foetal bovine serum (FBS), human autologous serum (AS) or serum-free medium. While FBS is used traditionally for in vitro chondrocyte expansion, an increase in demand and limited stocks are constantly increasing its price. FBS is a poorly defined mixture of components that can contain endotoxins, prion and viral proteins (Jochems et al., 2002; Selvaggi et al., 1997; van der Valk et al., 2010). Current good manufacturing practice (GMP) guidelines state that animal products should be replaced by human alternatives, wherever possible, for translating into cell therapies (Giancola et al., 2012; Unger et al., 2008; World Health Organisation, 1992; World Health Organization, 1991). Human AS would seem the ideal solution, but patient-to-patient variability can negatively impact upon key parameters, such as chondrocyte growth and quality (Harrison et al., 2000). Further, a relatively large volume of blood is required to perform chondrocyte expansion for ACI and this can be uncomfortable for the patients. A preferred alternative is defined serum-free growth media, but these media are supplemented with expensive growth factors that need to be replenished regularly during chondrocyte expansion. Given the issues described, other options are needed.

The use of platelet lysate for in vitro cell proliferation began in the 1980s (Choi et al., 1980). Doucet et al.
(2005) describe the preparation and application of human platelet lysate (HPL) for expanding mesenchymal stem cells. Further studies show both autologous and allogeneic HPL to be superior to FBS in enhancing cell proliferation (Burnouf et al., 2016; Hildner et al., 2015; Hofbauer et al., 2014; Kim et al., 2015; Trojahn Kølle et al., 2013). HPL eliminates the risk of cross-species contamination, solves standing ethical considerations and meets the GMP guidelines. In addition, it contains high levels of growth factors and cytokines and a range of vitamins and minerals that are also present in FBS and human AS (Hemeda et al., 2014; Shih and Burnouf, 2015). HPL is created from large donor pools, reducing the variability observed with other serum types. However, there are limitations to HPL use, including the potential risk of contamination with human viruses, some of which are screened for, including HIV. Many studies show that $5-10 \%(\mathrm{v} / \mathrm{v}) \mathrm{HPL}$ is superior to $10 \%(\mathrm{v} / \mathrm{v})$ FBS in supporting cell expansion in several different cell types (King and Buchwald, 1984; Mojica-Henshaw et al., 2013; Muraglia et al., 2014; Reinisch et al., 2007; Trojahn Kølle et al., 2013; Witzeneder et al., 2013). A HPL concentration of $10 \%(\mathrm{v} / \mathrm{v})$ supports cell proliferation at levels comparable to FBS (Burnouf et al., 2016; Hemeda et al., 2014; Hildner et al., 2015; Hofbauer et al., 2014). Only a handful of studies use HPL as an in vitro tool for human chondrocyte expansion (Gaissmaier et al., 2005; Hildner et al., 2015; Moreira Teixeira et al., 2012; Muraglia et al., 2014; Spreafico et al., 2009). Even fewer investigate the recovery of chondrocyte phenotype, known as re-differentiation, in 3-dimensional (3D) culture when the HPL is excluded from the re-differentiation media (Hildner et al., 2015). With ACI therapy in mind, it is important to ensure that the expanded chondrocytes have a chance to recover their chondrogenic phenotype in 3D culture without further exposure to relatively high levels of platelet-derived growth factors, which increase cell proliferation.

Stemulate $^{\mathrm{TM}}$ (Cook Regentec, Indianapolis, IN, USA), a commercially available source of HPL, is prepared according to GMP guidelines, using large donor pools from accredited blood centres. Given that Stemulate ${ }^{\mathrm{TM}}$ is used to expand a range of cell types, including adipose-derived mesenchymal stem cells (MSCs) and bone-marrow MSCs, it could be an alternative supplement to increase chondrocyte proliferation for cartilage cell therapy (Badowski et al., 2017; Juhl et al., 2016; Mangum et al., 2017; Riis et al., 2016; Søndergaard et al., 2017). Stemulate ${ }^{\mathrm{TM}}$ could reduce time in monolayer culture and reduce exposure to tissue-culture plastic, which in turn could reduce the risk of de-differentiation. The aim of the current work was to determine whether Stemulate ${ }^{\mathrm{TM}}$ could be a suitable alternative serum supplement to FBS for human chondrocyte expansion by assessing growth characteristics and cell morphology. Further, by using chondrogenic medium for both sets of chondrogenic pellets during re-differentiation in 
$3 \mathrm{D}$ culture, the aim was to assess the recovery of chondrocytes and determine their ability to produce ECM.

\section{Materials and Methods}

Chondrocyte isolation and monolayer expansion Fully informed consent was obtained from five individuals undergoing total knee replacement surgery at RJAH Hospital, Oswestry, with ethical approval (11/NW/0875). Full depth cartilage was removed from macroscopically normal areas of the femoral condyle from three male and two female individuals with a mean age of 67 years (range: 55-75 years). Chondrocytes were isolated following an established protocol (Harrison et al., 2000). Briefly, 100-300 mg of cartilage tissue were placed into $10 \mathrm{~mL}$ Dulbecco's modified Eagle's medium (DMEM)/F12 (11330-057; Gibco) containing 0.03 mg/ mL deoxyribonuclease I (D4263; Sigma-Aldrich) and $0.83 \mathrm{mg} / \mathrm{mL}$ type XI collagenase (C9407; SigmaAldrich). Digestion was performed for $16 \mathrm{~h}$ in a T25 tissue culture flask (Sarstedt) at $37^{\circ} \mathrm{C}$ and $5 \% \mathrm{CO}_{2}$. The digest was filtered through a $0.2 \mu \mathrm{m}$ cell strainer and chondrocytes were pelleted at $750 \times g$ for $10 \mathrm{~min}$. After that $>98 \%$ cell viability was verified using trypan blue (T8154; Sigma-Aldrich), the chondrocytes were plated into T175 tissue-culture flasks at a density of $5 \times 10^{4} \mathrm{cells} / \mathrm{cm}^{2}$ in DMEM/F12 supplemented with $0.5 \%(\mathrm{w} / \mathrm{v})$ penicillin-streptomycin-amphotericin (17-745E; Lonza), $0.5 \%$ (w/v) ascorbate (A4544; Sigma-Aldrich) and either $10 \%$ (v/v) FBS (10500064; Gibco) or $10 \%$ (v/v) Stemulate ${ }^{\mathrm{TM}}$ (PL-SP-100; Cook Regentec). Media were replenished three times weekly. Once $80 \%$ confluency was reached, the chondrocytes were passaged and re-seeded at a density of $5 \times 10^{4}$ cells $/ \mathrm{cm}^{2}$. Chondrocytes were cultured in monolayer until the end of passage 2 .

\section{Growth kinetics during monolayer expansion}

To assess growth kinetics during monolayer expansion, population doubling times (PDTs) were recorded at each passage and calculated using the following formula (McAteer and Davis, 2002):

$$
P D T=\frac{1}{\text { multiplication rate }}
$$

Multiplication rate $=\frac{3.32 \times[\log (\text { final cell number })-\log (\text { initial cell number })]}{}$ time difference

\section{Re-differentiation in 3D pellet culture in chondrogenic medium}

At the end of passage 2, the chondrocytes were detached and re-suspended in chondrogenic redifferentiation medium optimised from the Johnstone method (Johnstone et al., 1998), comprising DMEM/ F12 supplemented with $1 \%(\mathrm{v} / \mathrm{v}) \mathrm{FBS}, 1 \%(\mathrm{v} / \mathrm{v})$ nonessential amino acids (11140-035; Gibco), $1 \%$ (v/v) L-glutamine (G7513; Sigma-Aldrich), $0.5 \%$ (v/v) penicillin-streptomycin-amphotericin (17-745E;
Lonza), $0.5 \%(\mathrm{w} / \mathrm{v})$ ascorbate (A4544; SigmaAldrich), $1 \%(\mathrm{v} / \mathrm{v})$ insulin-transferrin-selenium (51500-056; Gibco), 20 ng/mL transforming growth factor- $\beta 1$ (100-21; Peprotech), $10 \mathrm{nM}$ dexamethasone (D4902; Sigma-Aldrich) and $3.2 \mu \mathrm{g} / \mathrm{mL}$ L-proline (P0380; Sigma-Aldrich). The chondrocytes $\left(2.5 \times 10^{5}\right.$ cells) were transferred to $1.5 \mathrm{~mL}$ Eppendorf ${ }^{\circledast}$ tubes and centrifuged at $750 \times g$ for $7 \mathrm{~min}$, to create spherical pellets. Pellets were cultured in $500 \mu \mathrm{L}$ of chondrogenic medium. Medium was replenished twice weekly.

\section{Pellet processing for analyses}

Pellets were assessed at day 0, 7, 14, 21 and 28. For biochemical assays, pellets $(n=5)$ were digested in $1 \mathrm{mg} / \mathrm{mL}$ proteinase $\mathrm{K}$ (25530-015; Ambion) in $100 \mathrm{mM}$ ammonium acetate (09691; Sigma-Aldrich) for $2 \mathrm{~h}$ at $60{ }^{\circ} \mathrm{C}$. Proteinase $\mathrm{K}$ was inactivated for $5 \mathrm{~min}$ at $100{ }^{\circ} \mathrm{C}$ and samples were stored at $-20^{\circ} \mathrm{C}$. For histology, pellets $(n=4)$ were placed onto Whatman filter paper (Whatman, Kent, UK), snap frozen in liquid-nitrogen-cooled n-hexane and stored at $-80^{\circ} \mathrm{C}$. For gene expression analysis, pellets $(n=3)$ were prepared for RNA extraction by homogenisation in $350 \mu$ L RLT lysis buffer containing $1 \%$ (v/v) $\beta$-mercaptoethanol (M6250; Sigma-Aldrich) using a $21 \mathrm{G}$ needle and syringe (1053393; QIAGEN) and stored at $-80^{\circ} \mathrm{C}$.

\section{Pellet cell number}

Cell number was determined using the PicoGreen ${ }^{\circledR}$ fluorescent DNA quantification kit (17916; Invitrogen), with lambda DNA as standard $(1 \mathrm{ng} / \mathrm{mL}-1 \mu \mathrm{g} / \mathrm{mL})$. Duplicate samples and standards were transferred to a 96-well plate and fluorescence was read at an excitation of $480 \mathrm{~nm}$ and emission of $520 \mathrm{~nm}$ using a FLUOstar Omega microplate reader (BMG, Ortenberg, Germany). Cell number was calculated using the widely reported value of 7.7 pg of DNA per chondrocyte (Kim et al., 1988).

\section{Total sGAG content in the pellets}

The total sGAG was determined using 1,9-dimethylmethylene blue (DMMB) (Farndale et al., 1986). All reagents were procured from SigmaAldrich. Chondroitin sulphate A from bovine trachea (C9819) was used as standard $(0-200 \mu \mathrm{g} / \mathrm{mL})$. In brief, $4 \mathrm{mg}$ DMMB (341088) were diluted in $250 \mathrm{~mL}$ distilled water containing $0.76 \mathrm{~g}$ glycine (G5516) and $0.595 \mathrm{~g}$ sodium chloride (S5886) to a final $\mathrm{pH}$ of 3.0. Duplicate samples and standards were transferred to a 96-well plate and mixed with $200 \mu \mathrm{L}$ of DMMB dye. Absorbance was read at $530 \mathrm{~nm}$ using a FLUOstar Omega microplate reader (BMG).

\section{Total collagen content in the pellets}

The total collagen content was determined by a hydroxyproline assay (Brown et al., 2001). All reagents were procured from Sigma-Aldrich. Hydroxyproline standards $(0-0.1 \mu \mathrm{g} / \mathrm{mL} ; \mathrm{H} 5,440-9)$ were prepared in distilled water. $100 \mu \mathrm{L}$ of each sample were hydrolysed 
Table 1. Genes used in qPCR analysis. Genes were selected to determine the chondrogenic phenotype of the cells and if the chondrocytes had de-differentiated to a hypertrophic state.

\begin{tabular}{|c|c|c|c|}
\hline Gene & Official name and species & Amplicon length & Entrez ID \\
\hline \multicolumn{4}{|c|}{$\begin{array}{r}\text { Reference genes } \\
\end{array}$} \\
\hline HPRT1 & $\begin{array}{l}\text { Hypoxanthine phosphoribosyltransferase } 1 \\
\text { (human) }\end{array}$ & 130 (NM_000194) & 3251 \\
\hline TBP & TATA box binding protein (human) & $\begin{array}{c}132 \text { (NM_001172085) } \\
132 \text { (NM_003194) }\end{array}$ & 6908 \\
\hline \multicolumn{4}{|c|}{ Chondrogenic markers } \\
\hline$A C A N$ & Aggrecan (human) & $\begin{array}{c}62 \text { (NM_001135) } \\
62 \text { (NM_013227) } \\
62 \text { (XM_001131727) } \\
62 \text { (XM_001131734) } \\
62 \text { (XM_00670419) }\end{array}$ & 176 \\
\hline COL2A1 & Collagen type 2 alpha 1 (human) & $\begin{array}{c}95 \text { (NM_001844) / } \\
95 \text { (XM_006719242) }\end{array}$ & 1280 \\
\hline SOX9 & SRY (sex determining region Y)-box 9 (human) & 112 (NM_000346) & 6662 \\
\hline \multicolumn{4}{|c|}{ De-differentiation markers } \\
\hline COL1A1 & Collagen type 1 alpha 1 (human) & $\begin{array}{c}118 \text { (NM_000088) } \\
118 \text { (NM_003257058) } \\
118 \text { (XM_005257059) } \\
118 \text { (XM_006721703) }\end{array}$ & 1277 \\
\hline \multicolumn{4}{|c|}{ Hypertrophic markers } \\
\hline ALK1/ACVRL1 & Activin A receptor type II-like 1 (human) & 74 (NM_000020) & 94 \\
\hline COL10A1 & Collagen type 10 alpha 1 (human) & 91 (NM_000493) & 1300 \\
\hline
\end{tabular}

in $100 \mu \mathrm{L}$ of $10 \mathrm{M}$ hydrochloric acid (19068) for $16 \mathrm{~h}$ at $108^{\circ} \mathrm{C}$. On cooling, the samples were neutralised with $800 \mu \mathrm{L}$ of $1 \mathrm{M}$ sodium hydroxide (S5881). Duplicate samples and standards were transferred to a 96-well plate. $100 \mu \mathrm{L}$ of oxidation buffer [600 $\mathrm{mL}$ isopropyl alcohol, $330 \mathrm{~mL}$ distilled water, $390 \mathrm{~mL}$ citrate/ acetate buffer ( $1 \mathrm{~L}$ consists of $34 \mathrm{~g}$ sodium hydroxide (S5881), $34 \mathrm{~g}$ citric acid monohydrate (C7129) and $120 \mathrm{~g}$ sodium acetate trihydrate (32318-M)), pH 6.0] were used as a negative control. Oxidation solution [100 $\mu \mathrm{L} ; 300$ mg chloramine T (402869) dissolved in $50 \mathrm{~mL}$ oxidation buffer] was added to all samples and standards. The plate was incubated at room temperature for $5 \mathrm{~min}$. Ehrlich's reagent [100 $\mu \mathrm{L} ; 6 \mathrm{~g}$ p-dimethylaminobenzaldehyde (156477) dissolved in a mixture of $16 \mathrm{~mL}$ of $50 \%$ perchloric acid (244252) and $52 \mathrm{~mL}$ of isopropyl alcohol] was added to each well and, then, the plate was sealed and incubated in a $60{ }^{\circ} \mathrm{C}$ water bath for $45 \mathrm{~min}$. Absorbance was measured at $570 \mathrm{~nm}$ using a FLUOstar Omega microplate reader (BMG) and total collagen was calculated using the widely reported multiplication factor of 7 (Sims et al., 2000).

qRT-PCR to assess gene expression in the pellets mRNA was extracted using the QIAGEN RNeasy mini kit as per manufacturer's instructions. mRNA was reverse-transcribed in a Progene thermocycler (Techne, Staffordshire, UK) using a high-capacity cDNA reverse transcription kit (4368814; Applied Biosystems) following the manufacturer's instructions. qRT-PCR was performed on three pellet replicates (from each patient) to determine gene expression relative to two reference genes, according to published guidelines (Bustin et al., 2009): hypoxanthine-guanine phosphoribosyltransferase-1 (HPRT1 human; RT00059066) (Foldager et al., 2009; Rushton et al., 2014) and TATA box-binding protein (TBP; QT00000721) (Foldager et al., 2009; PomboSuarez et al., 2008) were selected based on low coefficiencies of variance across both supplement types (data not shown). Several genes (Table 1) were chosen to determine the chondrogenic phenotype after redifferentiation. All genes, including reference genes, were procured from QIAGEN. Gene expression was measured relative to the reference genes and normalised to the cell number. Relative gene expression profiles were determined by the comparative $\mathrm{C}_{\mathrm{T}}$ method (Schmittgen and Livak, 2008).

\section{Histology of the frozen pellets}

The frozen pellets were mounted onto pre-cooled chucks with optimal cutting temperature (OCT) compound (00.090.112; Sakura Finetek, Zoeterwoude, the Netherlands). All stains were procured from VWR International. $7 \mu \mathrm{m}$-thick sections were collected onto poly-L-lysine pre-coated slides (MBC0102-54A; Cell Path, Newtown, UK) and stained with haematoxylin (350604T) and eosin (34197) or toluidine blue (340774Y), according to Roberts and Menage (2004). Sections were imaged by light microscopy (Leitz, Wetzlar, Leica Microsystems $\mathrm{GmbH}$, Stuttgart, Germany) using $\times 6.3, \times 25$ and $\times 40$ objective lenses. Images were captured using 
a DS-Fi1 camera and analysed with NIS-Elements BR imaging software (Nikon). Images were whitebalanced using Photoshop Elements (Adobe). To semi-quantify the toluidine blue staining intensity, four central images of each pellet were randomly selected and the integrated density was determined using Image Software (NIH) according to the published methodology (Jensen, 2013; Owida et al., 2017; Prasad and Prabhu, 2012).

\section{Statistical analyses}

All independent outcomes (PDTs, cell number, sGAG, total collagen, qPCR and staining intensity), patient variability and differences between the two supplement types over the time course were analysed using a multilevel model. Supplement type and time points were considered fixed variables and the patient was considered a random variable (random intercept). All qPCR data were log-transformed before the analysis, to make the data fit a normal distribution.

Cell number, sGAG and total collagen data $(n \geq 4$ per time point per patient, 5 patients in total) were expressed as mean \pm standard error of the mean (SEM). Gene expression data $(n=3$ per time point per patient, 5 patients in total) were shown as a box plot, with the box representing the second and third quartiles, the horizontal line inside the box representing the median and the whiskers either side of the box representing the lower and upper quartiles. All statistical analyses were performed with SPSS statistical software (version 24; IBM) and, for all analyses, $p<0.05$ was deemed to denote statistical significance.

\section{Results}

\section{Stemulate ${ }^{\mathrm{TM}}$ positively influenced proliferation of} chondrocytes in monolayer culture

For all 5 patients, the chondrocytes expanded in Stemulate $^{\mathrm{TM}}$ (mean PDT: $13.10 \pm 2.57 \mathrm{~d}$ ) proliferated quicker than the chondrocytes expanded in FBS (mean PDT: $25.07 \pm 6.98 \mathrm{~d}, p=0.050)$. Patient variability was considered not statistically significant $(p=0.48)$ in affecting the PDT. Both sets of chondrocytes underwent less than 2 absolute population doublings throughout passages 1, 2 and 3 (Fig. 1). No statistically significant difference was measured in population doublings between the two sera supplements $(p=0.527)$ or at any passage $(p=0.50)$. Patient variability was considered not statistically significant ( $p=0.445)$ in affecting population doublings.

Chondrocytes expanded in both FBS and Stemulate $^{\mathrm{TM}}$ were seeded at an equal cell density upon chondrocyte isolation, after which both sets of chondrocytes showed a significant increase in cell number over time ( $p<0.001$; Fig. 2). Chondrocytes expanded in Stemulate ${ }^{\mathrm{TM}}$ demonstrated a significantly larger increase in cell number as compared to chondrocytes expanded in FBS $(p=0.014)$. Patient variability was considered not statistically significant $(p=0.296)$ in affecting cell number in monolayer.

Fig. 3 shows the morphology of the human chondrocytes (day 4 of each culture) in the presence of either Stemulate ${ }^{\mathrm{TM}}$ or FBS during passage 0,1 and 2. For Stemulate ${ }^{\mathrm{TM}}$-expanded chondrocytes, markedly more chondrocytes were present and they appeared to cluster together at all passages. For both supplement types, chondrocytes appeared elongated and flattened, with little difference in their cell shape at all passages.

\section{Stemulate ${ }^{\mathrm{TM}}$ negatively influenced the re- differentiation potential of chondrocytes in 3D pellet culture}

To investigate whether the removal of Stemulate ${ }^{\mathrm{TM}}$ at the end of chondrocyte monolayer expansion resulted in delayed ECM production in 3D pellet culture, a $28 \mathrm{~d}$ time course was performed. 3D pellets were assessed for cell number (Fig. 4), total sGAG (Fig. 5), total collagen (Fig. 6) and gene expression by q-PCR (Fig. 7).

For both supplement types, cell number (Fig. 4) remained consistent throughout the time course $(p=0.84)$. This was expected since the 3D pellet conformation should enable the chondrocytes to recover their morphology and prevent further

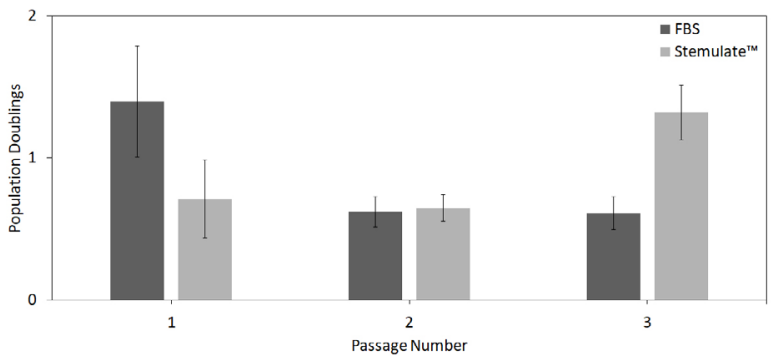

Fig. 1. Absolute population doublings of chondrocytes expanded in FBS and Stemulate ${ }^{\mathrm{TM}}$ sera at each of the three passages. Data are presented as mean $\pm \operatorname{SEM}(n=5)$.

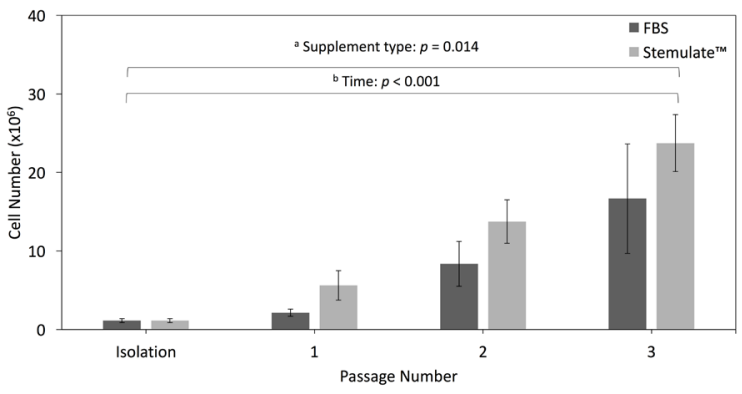

Fig. 2. Cell number during monolayer expansion of chondrocytes in FBS- and Stemulate ${ }^{\mathrm{TM}}$ supplemented sera. Cell number was calculated from cell counts during chondrocyte (seeded at an equal cell density) isolation and across three passages. Data are presented as mean $\pm \operatorname{SEM}(n=5)$. 


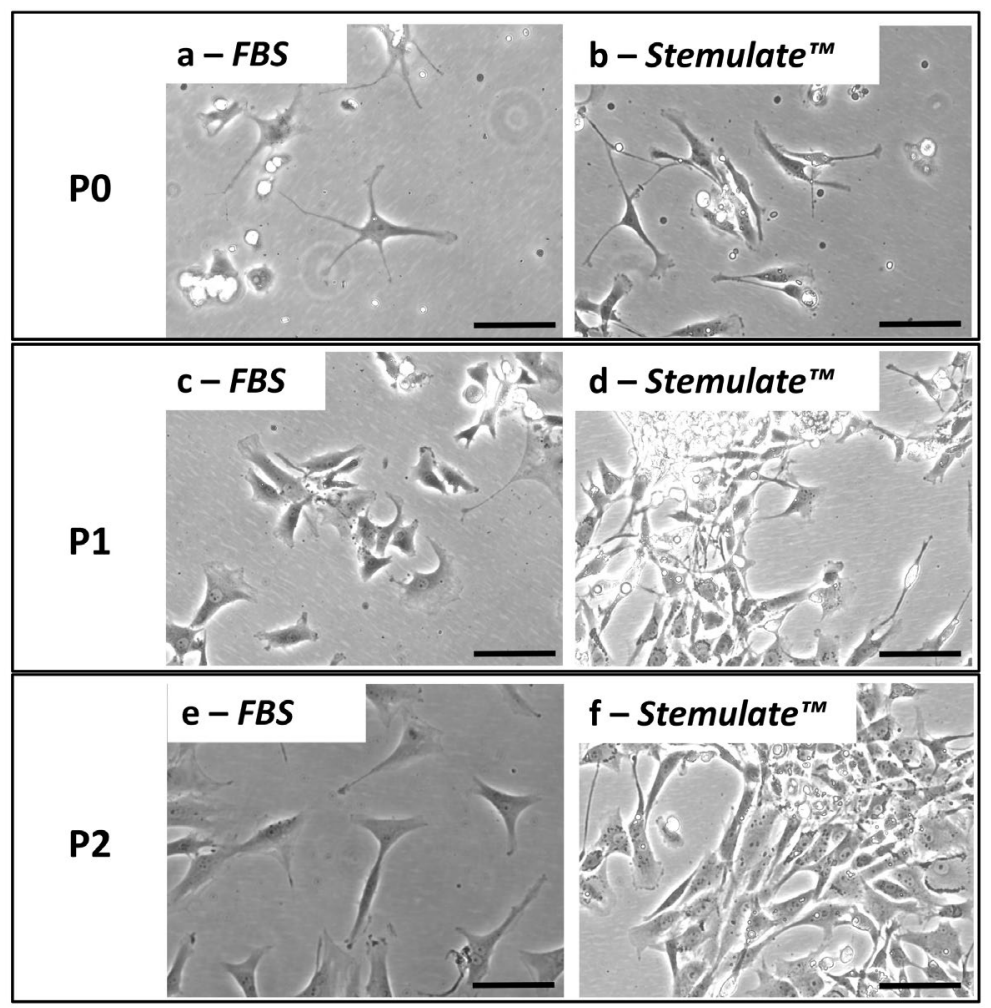

Fig. 3. Representative images of chondrocytes expanded in culture media supplemented with $10 \%$ (a,c,e) FBS and $(\mathbf{b}, \mathbf{d}, \mathbf{f})$ Stemulate $^{\mathrm{TM}}$ at passage $0-2$ (P 0-P 2). Images were taken at day 4 of each passage to allow the chondrocytes to adhere. All images were taken using the Nikon TS100 light microscope and $\times 20$ magnification. Images were acquired using the IPLab 3.2.6 software. Scale bars: $10 \mu \mathrm{m}$.

proliferation. Total sGAG (Fig. 5) and total collagen (Fig. 6) production were normalised to cell number. Chondrocytes expanded in both supplement types demonstrated a steady and significant increase in sGAG production across all time points $(p<0.001)$ (Fig. 5). sGAG concentration was higher in FBS as compared to Stemulate ${ }^{\mathrm{TM}}$ across all time points $(p=0.009)$, as determined by multi-level modelling. A significant sharp increase in sGAG concentration at day 14 was observed for FBS-expanded chondrocytes $(p<0.001)$, with a slight levelling off in sGAG production at day 28 for both supplements. No evidence of variability among individual patients at any time point was detected ( $p=0.60)$ (Fig. 5).

Collagen production demonstrated a significant interaction between treatment and time $(p=0.001)$ (Fig. 6). Both supplement types showed a similar pattern of relatively steady levels until a sharp increase between day 21 and 28, with levels being significantly higher in FBS as compared to Stemulate $^{\mathrm{TM}}(p=0.001)$. Again, there was no evidence of variability among individual patients at any time point $(p=0.26)$ (Fig. 6).

RT-qPCR was performed at day 0, 21 and 28; relative gene expression profiles were determined by the comparative $\mathrm{C}_{\mathrm{T}}$ method (Schmittgen and Livak, 2008) and normalised to the cell number. Expression of COL1A1, COL10A1 or ALK1 was not detected in either supplement type. For the key chondrogenic markers ACAN, COL2A1 and SOX9 there were striking differences between gene expression profiles in each supplement. ACAN expression increased over the time course in both supplements $(p<0.001$ for time), but was significantly higher in FBS- than Stemulate ${ }^{\mathrm{TM}}-$ expanded pellets at day $0(p<0.001)$ and day 21 ( $p=0.013)$. COL2A1 expression was significantly higher in FBS- than in Stemulate ${ }^{\mathrm{TM}}$ expanded pellets at day $0(p=0.033)$ and day 21 $(p=0.034)$. FBS-expanded pellets demonstrated a significantly higher expression of SOX9 at day 21 $(p=0.012)$ and day $28(p=0.002)$ when compared with Stemulate ${ }^{\mathrm{TM}}$-expanded pellets. There was no evidence of variability among patients for $A C A N(p=0.48)$ and COL2A1 expression $(p=0.33)$ or for a general change in COL2A1 $(p=0.20)$ and SOX9 expression $(p=0.15)$ over time (Fig. 7).

\section{FBS improved the quality of the ECM produced in $3 \mathrm{D}$ pellet culture}

Frozen chondrogenic pellets were sectioned $(7 \mu \mathrm{m})$ and stained with haematoxylin and eosin (H\&E) or toluidine blue to visualise general morphology and proteoglycan distribution, respectively (Fig. 8). At day 7, chondrocytes expanded in Stemulate ${ }^{\mathrm{TM}}$ appeared to form less stable and more fragile pellets when compared with chondrocytes expanded in FBS. Morphological differences seemed apparent in the cells occupying the periphery of the pellets. These cells appeared to be more fibroblastic in pellets created from the Stemulate ${ }^{\mathrm{TM}}$-expanded chondrocytes as compared to those created from FBSexpanded chondrocytes (Fig. 8). In both supplement types, there was a trend for the staining intensity of the chondrogenic pellets to increase over time. Pellets from FBS-expanded chondrocytes demonstrated an increase in metachromasia. This increase was quantitated using ImageJ software (Fig. 9), to confirm that, at day 21, FBS-expanded chondrocytes had a significantly more intense staining as compared

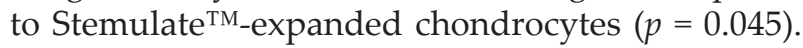



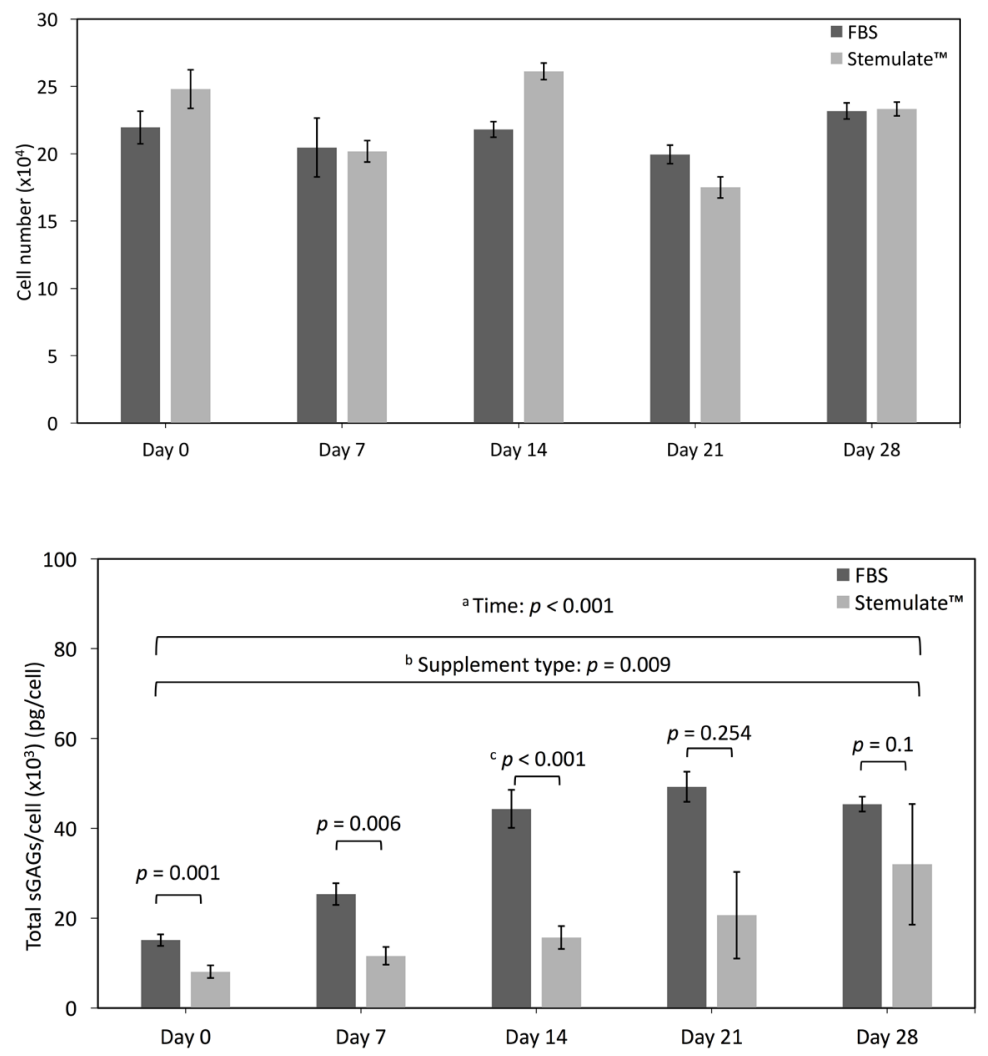

Fig. 4. Cell number in chondrogenic pellets created from chondrocytes expanded in FBS- and Stemulate ${ }^{\mathrm{TM}}$-supplemented sera over a $28 \mathrm{~d}$ time course. Data are presented as mean \pm SEM for day 0-21 $(n=5)$ and up to day $28(n=3)$.
Again, there was no evidence of variability among patients in staining intensity $(p=0.48)$.

\section{Discussion}

This study focused on two sera supplements and their effects on human chondrocyte proliferation and the chondrocytes' subsequent recovery using standard chondrogenic differentiation protocols. To our knowledge, this is the only study providing a detailed analysis of ECM production from 5 individuals. However, it was not possible to compare AS among donors because the existing ethically approved protocol does not allow taking a sufficient volume of blood to provide sera for monolayer in vitro expansion to the end of passage 2 , representing a limitation of the study. Another limitation was that only chondrocytes obtained from total knee replacement were evaluated. Therefore, caution must be used when interpreting these data as compared with chondrocytes sourced from patients undergoing $\mathrm{ACI}$, as the patient populations for these treatments differ (for example, patients undergoing $\mathrm{ACI}$ tend to be younger than those undergoing joint replacement surgery). Despite these limitations, four key points were demonstrated. First, Stemulate ${ }^{\mathrm{TM}}$ increased chondrocyte proliferation when compared to FBS. This result was not surprising since several studies report that HPL increases cell proliferation in many cell types (Crespo-Diaz et al., 2011; Hemeda et al., 2014; Hildner et al., 2015; Luttenberger et al., 2000; Mojica-Henshaw et al., 2013). Second, monolayer expansion of human chondrocytes in Stemulate ${ }^{\mathrm{TM}}$ negatively influenced the stability of the 3D pellets as compared to expansion in FBS: these chondrogenic pellets disintegrated easily when sectioned, slightly losing the pellet form - especially in the cells occupying the periphery, which appeared to be more fibroblastic. Third, total sGAG synthesis by Stemulate ${ }^{\mathrm{TM}}$-expanded chondrocytes lagged behind the FBS-expanded ones. Fourth, expansion in Stemulate ${ }^{\mathrm{TM}}$ negatively influenced chondrogenic gene expression in 3D pellets as compared to FBS.

There is clear evidence to confirm that 5-10\% $(\mathrm{v} / \mathrm{v})$ HPL is more effective in supporting monolayer expansion of human MSCs than both FBS and AS at the same concentration range (Bieback et al., 2009; Juhl et al., 2016; Trojahn Kølle et al., 2013). Further, both Bieback et al. (2009) and Juhl et al. (2016) report that HPL supported long term monolayer expansion whilst still maintaining the MSCs phenotype and their differentiation potential. Given these positive data, herein it was established that Stemulate ${ }^{\mathrm{TM}}$ was better than FBS at increasing chondrocyte proliferation in monolayer culture. No published studies have used Stemulate ${ }^{\mathrm{TM}}$ for chondrocyte expansion, but increased proliferation is shown when using derivatives of HPL. Spreafico et al. (2009) compare the effects of platelet rich plasma (PRP), platelet poor plasma (PPP) and FBS on human chondrocytes over a $20 \mathrm{~d}$ cell proliferation time course, with PRP resulting the most stimulatory in terms of chondrocyte proliferation. Hildner et al. (2015) report that $5 \%-10 \%$ HPL significantly increase human chondrocyte proliferation as compared to FBS. From 


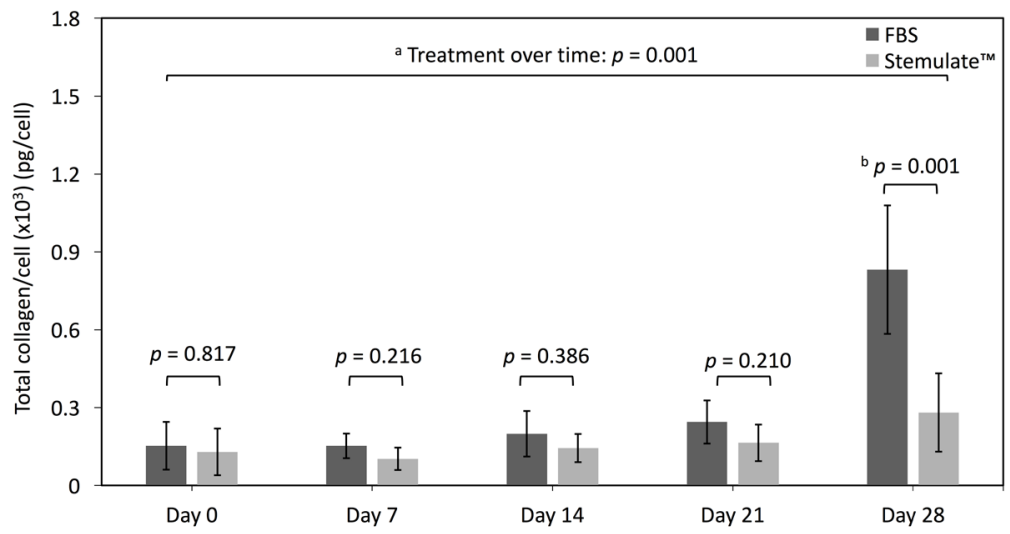

Fig. 6. Total collagen production per cell in chondrogenic pellets created from chondrocytes expanded in FBS- and Stemulate ${ }^{\mathrm{TM}}$-supplemented sera over a 28 d time course. Data are presented as mean \pm SEM for day $0-21(n=5)$ and up to day $28(n=3)$. a denotes statistical significance for time. ${ }^{\mathrm{b}}$ denotes statistical significance at day 28.
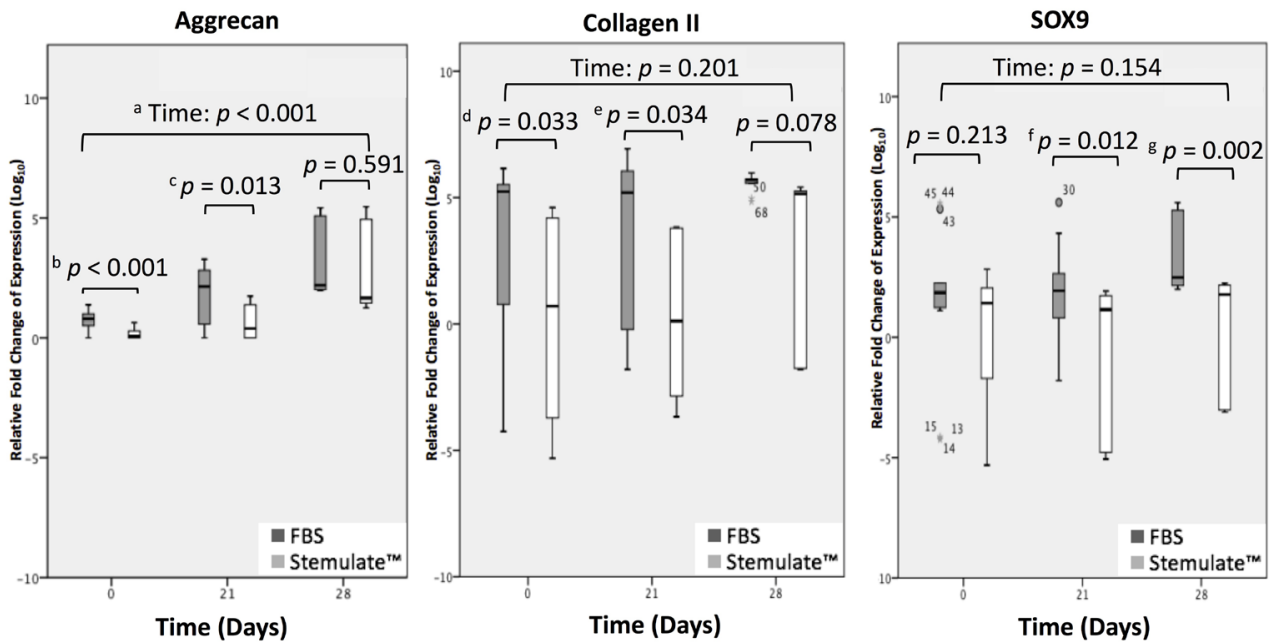

Fig. 7. Box and whisker plot of gene expression profiles of the chondrogenic pellets created from chondrocytes expanded in FBS- and Stemulate ${ }^{\mathrm{TM}}$-supplemented sera. Data are expressed relative to the reference genes, obtained from 5 patients using 3 experimental pellet replicates per patient, and determined by using the comparative $\mathrm{C}_{\mathrm{T}}$ method. ${ }^{\mathrm{a}}$ denotes statistical significance for time. ${ }^{\mathrm{b}}$ denotes statistical significance for aggrecan expression at day $0 .{ }^{c}$ denotes statistical significance for aggrecan expression between supplement types at day $21 .{ }^{\mathrm{d}}$ denotes statistical significance for collagen II expression between supplement types at day $0 .{ }^{\mathrm{e}}$ denotes statistical significance for collagen II expression between supplement types at day $21 .{ }^{\mathrm{f}}$ denotes statistical significance for SOX9 expression between supplement types at day 21. ${ }^{g}$ denotes statistical significance for SOX9 expression between supplement types at day 28.

these studies and the current, it is evident that HPL increases the proliferation of human chondrocytes in monolayer culture.

In the current study, no morphological differences were observed in human chondrocytes that were monolayer-expanded in Stemulate ${ }^{\mathrm{TM}}$ or FBS. No other published study has investigated morphological differences between human chondrocytes expanded in HPL or FBS. However, Trojahn-Kølle et al. (2013) report morphological differences in monolayerexpanded MSCs, appearing smaller and less spindle-like when cultured in HPL as compared with FBS. In the current study, 3D pellets from human chondrocytes expanded in monolayer in Stemulate $^{\mathrm{TM}}$ created more fragile, less compact pellets as compared to those expanded in FBS, as seen by qualitative histological assessment. These chondrogenic pellets disintegrated easily, losing their pellet form, when prepared for histological analysis, resulting in a more difficult sectioning of the Stemulate ${ }^{\mathrm{TM}}$-expanded pellets at day 7 . This was not assessed quantitatively but was a consistent observation throughout the study.

Very few studies use HPL with human chondrocytes and even fewer investigate sGAG production in $3 \mathrm{D}$ pellets. Following a published 3D pellet chondrogenic differentiation protocol (Johnstone et al., 1998; Pittenger, 1999), it was demonstrated that FBS-expanded human chondrocytes generated significantly more sGAG than Stemulate ${ }^{\mathrm{TM}}$-expanded human chondrocytes across a 4-week time course. These results were opposite to the findings of Hildner et al. (2015), who report that HPL-expanded chondrocytes produce more sGAG than FBSexpanded chondrocytes in micromass pellets created from the same chondrogenic differentiation 
protocol used in this study, over a 5-week period. After a 5-week culture period, a more intense sGAG staining is observed in HPL-expanded human chondrogenic pellets, compared to FBS pellets (Hildner et al., 2015). These differences could be due to the supplement types, since Stemulate ${ }^{\mathrm{TM}}$ was used in the current study, whereas Hildner et al. (2015) use a HPL generated in their own laboratory from PRP obtained from 36 expired thrombocyte concentrates produced at a transfusion blood centre. 5 batches of HPL are characterised by Quantikine ELISA for these experiments, but no further details on the characterisation are given (Hildner et al., 2015). Furthermore, in the current study, the 3D pellets were cultured in chondrogenic medium without HPL, whereas Hildner et al. (2015) add HPL into 3D pellet cultures.

In contrast to sGAG, total collagen production levels were found to be quite low throughout the 3D pellet culture 4-week time course. Despite this, collagen production by Stemulate ${ }^{\mathrm{TM}}$-expanded human chondrocytes appeared to lag behind FBSexpanded human chondrocytes. Gaissmaier et al. (2005) also observe that HPL-expanded chondrocytes seeded into 3D alginate beads produce low levels of collagen over a shorter time course of $14 \mathrm{~d}$.

In the $3 \mathrm{D}$ pellet cultures, genes that determine chondrocyte differentiation state were investigated. De-differentiation was investigated through the relative expression of COL1A1 (Benya et al., 1978; Brew et al., 2010) and hypertrophy through the relative expression of COL10A1 (Caron et al., 2012; Dell' Accio et al., 2001) and ALK1 (Blaney Davidson et al., 2009; Dell' Accio et al., 2001). ALK1 is up-regulated during monolayer expansion, due to a loss of in vivo cartilage formation potential, and is associated with irreversible chondrocyte de-differentiation (Blaney Davidson et al., 2007; Blaney Davidson et al., 2009; Dell' Accio et al., 2001). None of these genes were detected in 3D pellets derived from either Stemulate ${ }^{\mathrm{TM}}$ - or FBS-expanded human chondrocytes, suggesting that the human chondrocytes had not undergone de-differentiation or hypertrophy. In addition, chondrogenic capacity was assessed through the relative expression of COL2A1, ACAN and SOX9. COL2A1 and ACAN are necessary for ECM formation and the transcription factor $S O X 9$ regulates chondrocyte proliferation, chondrogenesis and transition to a non-hypertrophic state. Expression of COL2A1 and ACAN declines following prolonged monolayer culture, particularly after passage 4 (Schulze-Tanzil et al., 2002). For both these ECM markers, an increase was found across the 4-week time course. However, a much larger increase in relative gene expression was expected, especially by day 28 , as this is found in similar published studies (Hildner et al., 2015). An explanation could be that nutrient saturation was approached

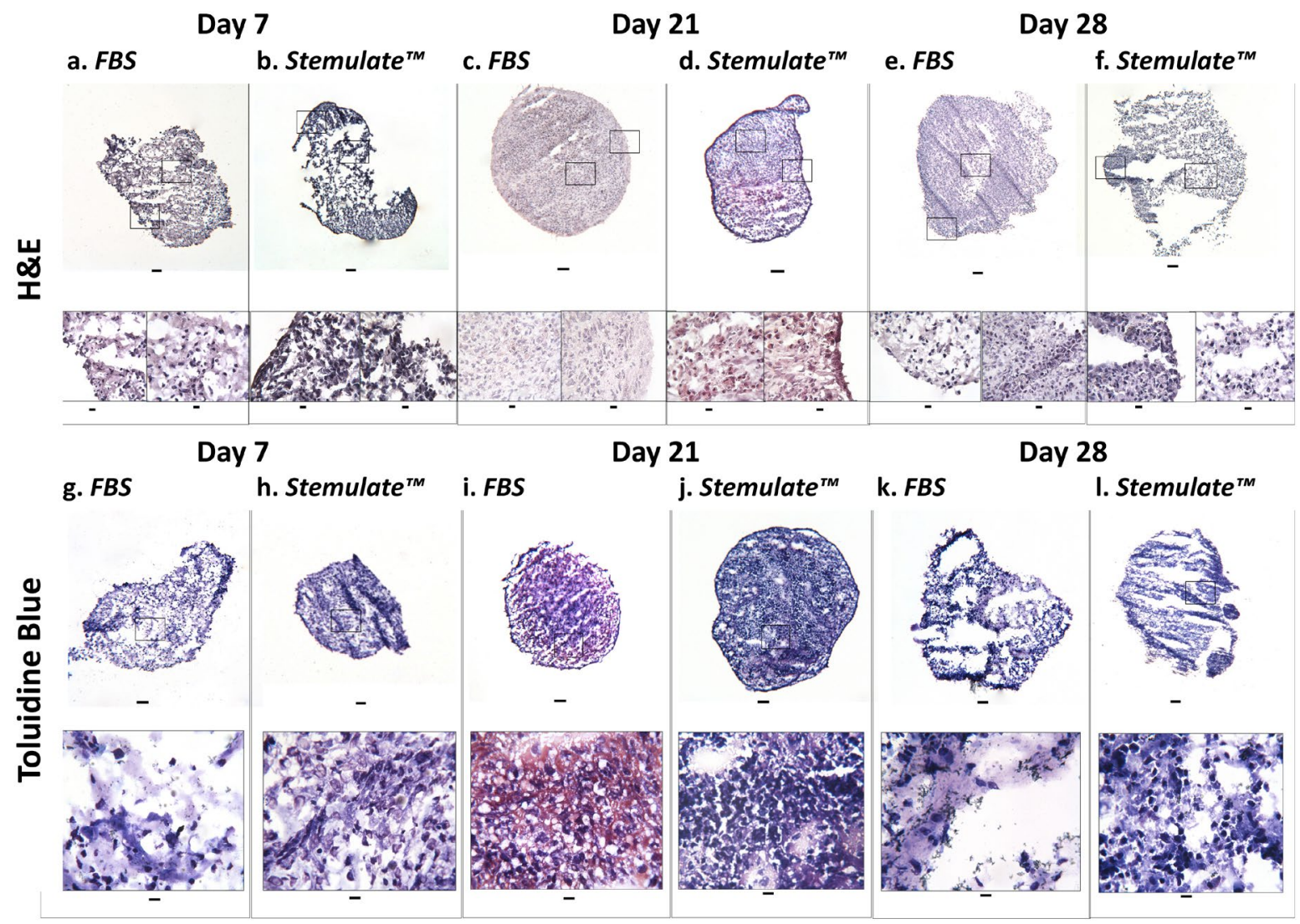

Fig. 8. Representative histological images from the centre of the FBS- and Stemulate ${ }^{\mathrm{TM}}$-expanded chondrogenic pellets across the $28 \mathrm{~d}$ time course. (a-f) Pellets stained with haematoxylin and eosin (H\&E) to assess overall morphology. (g-1) Pellets stained with toluidine blue to assess proteoglycan content. Insert images are higher-powered images of the regions marked with a solid line. Scale bars: $100 \mu \mathrm{m}$. 


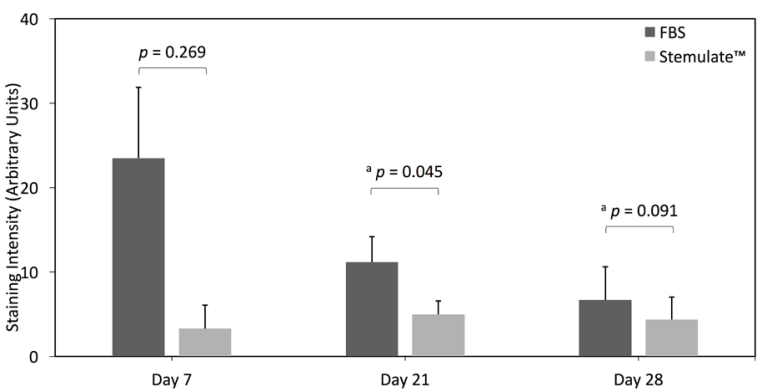

Fig. 9. Semi-quantification of toluidine-blue-stained chondrogenic pellets, demonstrating an increase in metachromasia, determined by integrated density analysis using ImageJ imaging software (version $24)$. Data are presented as mean \pm SEM for day 0-21 $(n=5)$ and up to day $28(n=3)$. ${ }^{\text {a denotes }}$ statistical significance for staining intensity between supplement types at day 21.

before day 28. Overall, SOX9 gene expression was more striking in FBS 3D pellets when compared to Stemulate ${ }^{\mathrm{TM}}$, indicating that the FBS-expanded human chondrocytes recovered chondrogenic potential more quickly. Taken together, these findings suggest that Stemulate ${ }^{\mathrm{TM}}$ caused a delay in the recovery of chondrogenic phenotype following monolayer expansion. It would have been interesting to perform q-PCR on the monolayer chondrocytes prior to seeding into pellets and to compare the relative gene expression of the chondrocytes before and during pellet culture. This would have determined how the relative gene expression levels would have changed following chondrogenic differentiation. However, the chondrocytes used were primary isolated chondrocytes and monolayerexpanded up to passage 2 , which limited cell number and prohibited the use of q-PCR analysis on the monolayer chondrocytes.

The multilevel modelling analyses performed allowed the comparison of the treatments over the time course and the exploration of the impact of patient variability (Hox, 2010; Vaughn, 2008). One of the limitations of the study was that cartilage was obtained from joints that were potentially osteoarthritic. OA is classified as a whole-joint disease and, although the cartilage was taken from macroscopically normal areas, chondrocytes could still have had a sub-chondrogenic phenotype upon differentiation. A previous study shows that osteoarthritic chondrocytes express higher levels of ALK1 (Blaney Davidson et al., 2009), but ALK1 expression was not detected in the monolayerexpanded chondrocytes. Patient variability was expected, but no statistical evidence was found for a patient-specific influence on any of the measured outcomes. Clearly more work needs to be done, but the current work demonstrated that although Stemulate ${ }^{\mathrm{TM}}$ led to rapid proliferation, it affected the re-differentiation potential of human chondrocytes. These findings demonstrated that
Stemulate ${ }^{\mathrm{TM}}$ induced a sub-chondrogenic phenotype upon differentiation or enhanced monolayerinduced chondrocyte de-differentiation and reduced chondrogenic capacity. Therefore, it should be used with caution when expanding chondrocytes for clinical use.

\section{Acknowledgments}

We are grateful for the financial support kindly provided by the Orthopaedic Institute Ltd., The Robert Jones and Agnes Hunt Orthopaedic Hospital, Oswestry, Shropshire, UK. We would like to thank Cook Regentec for supplying the Stemulate ${ }^{\mathrm{TM}}$, Dr Sharon Owen and Mrs Annie Kerr for obtaining patient consent and Dr Helen McCarthy for technical guidance.

This project was funded by the Institute of Orthopaedics Ltd., Oswestry, Shropshire, UK.

There are no competing interests for any of the named authors.

\section{References}

Badowski M, Muise A, Harris DT (2017) Tissues, successful clinical use of long term frozen adipose. Cytotherapy 19: S150-S151.

Benya PD, Shaffer JD (1982) Dedifferentiated chondrocytes reexpress the differentiated collagen phenotype when cultured in agarose gels. Cell 30: 215-224.

Benya P, Padilla S, Nimni M (1978) Independent regulation of collagen types by chondrocytes during the loss of differentiated function in culture. Cell 15: 1313-1321.

Bhosale AM, Kuiper JH, Johnson WEB, Harrison PE, Richardson JB (2009) Midterm to long-term longitudinal outcome of autologous chondrocyte implantation in the knee joint: a multilevel analysis. Am J Sports Med 37: 131-138.

Bieback K, Hecker A, Kocaömer A, Lannert H, Schallmoser K, Strunk D, Klüter H (2009) Human alternatives to fetal bovine serum for the expansion of mesenchymal stromal cells from bone marrow. Transl Clin Res 27: 2331-2341.

Blaney Davidson EN, van der Kraan PM, van den Berg WB (2007) TGF-beta and osteoarthritis. Osteoarthr Cartil 15: 597-604.

Blaney Davidson EN, Remst DF, Vitters EL, van Beuningen HM, Blom AB, Goumans MJ, van den Berg WB, van der Kraan PM (2009) Increase in ALK1/ALK5 ratio as a cause for elevated MMP-13 expression in osteoarthritis in humans and mice. J Immunol 182: 7937-7945.

Brew CJ, Clegg PD, Boot-Handford RP, Andrew JG, Hardingham T (2010) Gene expression in human chondrocytes in late osteoarthritis is changed in both 
fibrillated and intact cartilage without evidence of generalised chondrocyte hypertrophy. Ann Rheum Dis 69: 234-240.

Brittberg M, Lindahl A, Nilsson A, Ohlsson C, Isaksson O, Peterson L (1994) Treatment of deep cartilage defects in the knee with autologous chondrocyte implantation. N Engl J Med 331: 889-895.

Brown S, Worsfold M, Sharp C (2001) Microplate assay for the measurement of hydroxyproline in acidhydrolyzed tissue samples. Biotechniques 30: 38-42.

Burnouf T, Strunk D, Koh MBC, Schallmoser K (2016) Human platelet lysate: replacing fetal bovine serum as a gold standard for human cell propagation?. Biomaterials 76: 371-387.

Bustin SA, Benes V, Garson JA, Hellemans J, Huggett J, Kubista M, Mueller R, Nolan T, Pfaffl MW, Shipley GL, Vandesompele J, Wittwer CT (2009) The MIQE guidelines: minimum information for publication of quantitative real-time PCR experiments. Clin Chem 55: 611-622.

Caron MMJ, Emans PJ, Coolsen MME, Voss L, Surtel DAM, Cremers A, van Rhijn LW, Welting TJM (2012) Redifferentiation of dedifferentiated human articular chondrocytes: comparison of 2D and 3D cultures. Osteoarthr Cartil 20: 1170-1178.

Choi YC, Morris GM, Sokoloff L (1980) Effect of platelet lysate on growth and sulfated glycosaminoglycan synthesis in articular chondrocyte cultures. Arthritis Rheum 23: 220-224.

Crespo-Diaz R, Behfar A, Butler GW, Padley DJ, Sarr MG, Bartunek J, Dietz AB, Terzic A (2011) Platelet lysate consisting of a natural repair proteome supports human mesenchymal stem cell proliferation and chromosomal Satability. Cell Transplant 20: 797811.

Davies-Tuck ML, Wluka AE, Wang Y, Teichtahl AJ, Jones G, Ding C, Cicuttini FM (2008) The natural history of cartilage defects in people with knee osteoarthritis. Osteoarthr Cartil 16: 337-342.

Dell'Accio F, De Bari C, Luyten FP (2001) Molecular markers predictive of the capacity of expanded human articular chondrocytes to form stable cartilage in vivo. Arthritis Rheum 44: 1608-1619.

Doucet C, Ernou I, Zhang YZ, LLense JR, Begot L, Holy X (2005) Platelet lysates promote mesenchymal stem cell expansion: a safety substitute for animal serum in cell-based applications. J Cell Physiol 205: 228-236.

Farndale RW, Buttle DJ, Barrett AJ (1986) Improved quantitation and discrimination of sulphated glycosaminoglycans by use of dimethylmethylene blue. Biochim Biophys Acta 883: 173-177.

Foldager CB, Munir S, Ulrik-Vinther M, Soballe K, Bunger C, Lind M (2009) Validation of suitable house keeping genes for hypoxia-cultured human chondrocytes. BMC Mol Biol 9: 94.

Gaissmaier C, Fritz J, Krackhardt T, Flesch I, Aicher WK, Ashammakhi N (2005) Effect of human platelet supernatant on proliferation and matrix synthesis of human articular chondrocytes in monolayer and three-dimensional alginate cultures. Biomaterials 26: 1953-1960.

Giancola R, Bonfini T, Iacone A (2012) Cell therapy: cGMP facilities and manufacturing. Muscles Ligaments Tendons J 2: 243-247.

Harrison PE, Ashton IK, Johnson WE, Turner SL, Richardson JB, Ashton BA (2000) The in vitro growth of human chondrocytes. Cell Tissue Bank 1: 255-260.

Hemeda H, Giebel B, Wagner W (2014) Evaluation of human platelet lysate versus fetal bovine serum for culture of mesenchymal stromal cells. Cytotherapy 16: $170-178$.

Henderson IJP, Tuy B, Connell D, Oakes B, Hettwer WH (2003) Prospective clinical study of autologous chondrocyte implantation and correlation with MRI at three and 12 months. J Bone Joint Surg 85B: 1060-1066.

Hildner F, Eder MJ, Hofer K, Aberl J, Redl $\mathrm{H}$, Griensven M van, Gabriel C, PeterbauerScherb A (2015) Human platelet lysate successfully promotes proliferation and subsequent chondrogenic differentiation of adipose-derived stem cells: a comparison with articular chondrocytes. J Tissue Eng Regen Med 9: 808-818.

Hofbauer P, Riedl S, Witzeneder K, Hildner F, Wolbank S, Groeger M, Gabriel C, Redl H, Holnthoner W (2014) Human platelet lysate is a feasible candidate to replace fetal calf serum as medium supplement for blood vascular and lymphatic endothelial cells. Cytotherapy 16: 1238-1244.

Hox JJ (2010) Multilevel analysis: techniques and applications. 2nd edition, New York, Routledge.

Jensen EC (2013) Quantitative analysis of histological staining and fluorescence using ImageJ. Anat Rec 296: 378-381.

Jochems CE, van der Valk JB, Stafleu FR, Baumans $\mathrm{V}$ (2002) The use of fetal bovine serum: ethical or scientific problem?. Altern Lab Anim 30: 219-227.

Johnstone B, Hering TM, Caplan AI, Goldberg VM, Yoo JU (1998) In vitro chondrogenesis of bone marrow-derived mesenchymal progenitor cells. Exp Cell Res 238: 265-272.

Juhl M, Tratwal J, Follin B, Søndergaard RH, Kirchhoff M, Ekblond A, Kastrup J, Haack-Sørensen M (2016) Comparison of clinical grade human platelet lysates for cultivation of mesenchymal stromal cells from bone marrow and adipose tissue. Scand J Clin Lab Invest 76: 93-104.

Kang SW, Yoo SP, Kim BS (2007) Effect of chondrocyte passage number on histological aspects of tissue-engineered cartilage. Bio Mater Eng 17: 269276.

Kim H, Prasain N, Vemula S, Ferkowicz MJ, Yoshimoto M, Voytik-Harbin SL, Yoder MC (2015) Human platelet lysate improves human cord blood derived ECFC survival and vasculogenesis in three dimensional (3D) collagen matrices. Microvasc Res 101: 72-81.

Kim YJ, Sahab RLY, Doongab JYH, Grodzinskyab AJ (1988) Fluorometric assay of DNA in cartilage 
explants using Hoechst 33258. Anal Biochem 174: 168-176.

King GL, Buchwald S (1984) Characterization and partial purification of an endothelial cell growth factor from human platelets. J Clin Invest 73: 392-396.

Luttenberger T, Schmid-Kotsas A, Menke A, Siech M, Beger H, Adler G, Grünert A, Bachem MG (2000) Platelet-derived growth factors stimulate proliferation and extracellular matrix synthesis of pancreatic stellate cells: implications in pathogenesis of pancreas fibrosis. Lab Invest 80: 47-55

Mangum LH, Natesan S, Stone II R, Wrice NL, Larson DA, Florell KF, Christy BA, Herzig MC, Cap AP, Christy RJ (2017) Tissue source and cell expansion condition influence phenotypic changes of adiposederived stem cells. Stem Cells Int 2017: 1-15.

McAteer JA, Davis JM (2002) Basic cell culture techniques and the maintenance of cell lines. In Basic cell culture, 2nd edition, Oxford University Press, Oxford, pp 135-186.

Mistry H, Connock M, Pink J, Shyangdan D, Clar C, Royle P, Court R, Biant LC, Metcalfe A, Waugh N (2017) Autologous chondrocyte implantation in the knee: systematic review and economic evaluation. Health Technol Assess (Rockv). 21: 1-294.

Mojica-Henshaw MP, Jacobson P, Morris J, Kelley L, Pierce J, Boyer M (2013) Serum-converted platelet lysate can substitute for fetal bovine serum in human mesenchymal stromal cell cultures. Cytotherapy 15: 1458-1468.

Moreira Teixeira LS, Leijten JCH, Wennink JWH, Chatterjea AG, Feijen J, van Blitterswijk CA, Dijkstra PJ, Karperien M (2012) The effect of platelet lysate supplementation of a dextran-based hydrogel on cartilage formation. Biomaterials 33: 3651-3661.

Muraglia A, Ottonello C, Spanò R, Dozin B, Strada P, Grandizio M, Cancedda R, Mastrogiacomo M (2014) Biological activity of a standardized freezedried platelet derivative to be used as cell culture medium supplement. Platelets 25: 211-222.

Nawaz SZ, Bentley G, Briggs TW, Carrington RW, Skinner JA, Gallagher KR, Dhinsa BS (2014) Autologous chondrocyte implantation in the knee: mid-term to long-term results. J Bone Joint Surg 96: 824-830.

Owida H, de Las Heras Ruiz T, Dhillon A, Yang Y, Kuiper N (2017) Co-culture of chondrons and mesenchymal stromal cells reduces the loss of collagen VI and improves extracellular matrix production. Histochem Cell Biol 148: 625-638.

Pittenger MF (1999) Multilineage potential of adult human mesenchymal stem cells. Science 284: 143-147.

Pombo-Suarez M, Calaza M, Gomez-Reino JJ, Gonzalez A (2008) Reference genes for normalization of gene expression studies in human osteoarthritic articular cartilage. BMC Mol Biol 9: 17.

Prasad K, Prabhu GK (2012) Image analysis tools for evaluation of microscopic views of immunohistochemically stained specimen in medical research. J Med Syst 36: 2621-2631.
Reinisch A, Bartmann C, Rohde E, Schallmoser K, Bjelic-Radisic V, Lanzer G (2007) Humanized system to propagate cord blood-derived multipotent mesenchymal stromal cells for clinical application. Regen Med 2: 371-382.

Riis S, Molgaard Nielsen F, Pablo Pennisi C, Zachar V, Fink T (2016) Comparative analysis of media and supplements on initiation and expansion of adipose-derived stem cells. Stem Cells Transl Med 5: 314-324.

Roberts S, Menage J (2004) Microscopic methods for the analysis of engineered tissues. Methods Mol Biol 238: 171-195.

Rushton MD, Reynard LN, Barter MJ, Refaie R, Rankin KS, Young DA, Loughlin J (2014) Characterization of the cartilage DNA methylome in knee and hip osteoarthritis. Arthritis Rheumatol 66: 2450-60.

Schmittgen TD, Livak KJ (2008) Analyzing RealTime PCR Data by the comparative CT method. Nat Protoc 3: 1101-1108.

Schnabel M, Marlovits S, Eckhoff G, Fichtel I, Gotzen L, Vecsei V, Schlegel J (2002) Dedifferentiationassociated changes in morphology and gene expression in primary human articular chondrocytes in cell culture. Osteoarthr Cartil 10: 62-70.

Schulze-Tanzil G (2009) Activation and dedifferentiation of chondrocytes: implications in cartilage injury and repair. Ann Anat 191: 325-338.

Schulze-Tanzil G, de Souza P, Villegas Castrejon H, John T, Merker HJ, Scheid A (2002) Redifferentiation of dedifferentiated human chondrocytes in highdensity cultures. Cell tissue Res 308: 371-379.

Selvaggi TA, Walker RE, Fleisher TA (1997) Development of antibodies to fetal calf serum with arthus-like reactions in human immunodeficiency virus-infected patients given syngeneic lymphocyte infusions. Blood 89: 776-779.

Shih DTB, Burnouf T (2015) Preparation, quality criteria, and properties of human blood platelet lysate supplements for ex vivo stem cell expansion. N Biotechnol 32: 199-211.

Sims TJ, Avery NC, Bailey AJ (2000) Quantitative determination of collagen crosslinks. In Methods Mol Biol, edition CH Streuli, ME Grant, Humana Press, Totowa, NJ, USA, 139: 11-26.

Søndergaard R, Follin B, Lund L, Juhl M, Ekblond A, Kastrup J, Haack-Sørensen M (2017) Senescence and quiescence in adipose-derived stromal cells: effects of human platelet lysate, fetal bovine serum and hypoxia. Cytotherapy 19: 95-106.

Spreafico A, Chellini F, Frediani B, Bernardini G, Niccolini S, Serchi T, Collodel G, Paffetti A, Fossombroni V, Galeazzi M, Marcolongo R, Santucci A (2009) Biochemical investigation of the effects of human platelet releasates on human articular chondrocytes. J Cell Biochem 108: 1153-1165.

Trojahn Kølle SF, Oliveri RS, Glovinski P V, Kirchhoff M, Mathiasen AB, Elberg JJ, Andersen PS, Drzewiecki KT, Fischer-Nielsen A (2013) Pooled 
human platelet lysate versus fetal bovine seruminvestigating the proliferation rate, chromosome stability and angiogenic potential of human adipose tissue-derived stem cells intended for clinical use. Cytotherapy 15: 1086-1097.

Unger C, Skottman H, Blomberg P, Sirac dilber M, Hovatta O (2008) Good manufacturing practice and clinical-grade human embryonic stem cell lines. Hum Mol Genet 17: 48-53.

van der Valk J, Mellor D, Brands R, Fischer R, Gruber F, Gstraunthaler G, Hellebrekers L, Hyllner J, Jonker FH, Prieto P, Thalen M, Baumans V (2010) The humane collection of fetal bovine serum and possibilities for serum-free cell and tissue culture. Toxicol In Vitro 18: 1-12.

Vaughn BK (2008) Data analysis using regression and multilevel/hierarchical models, by Gelman. J Educ Meas 45: 94-97.

Witzeneder K, Lindenmair A, Gabriel Cfyz, Holler K, Theiss D, Redl H (2013) Human-derived alternatives to fetal bovine serum in cell culture. Transfus Med Hemother 40: 417-423.

World Health Organisation (1992) Good manufacturing practices for pharmaceutical products.
In WHO expert committee on specifications for pharmaceutical preparation. Thirtysecond report, Geneva, pp 14-79.

World Health Organization (1991) Good manufacturing practices for biological products. In Annex 3, WHO good manufacturing practices for biological products. Replacement1 of Annex 1 of WHO Technical Report Series, No. 822, Geneva, pp 20-30.

\section{Web Reference}

1. https://www.nice.org.uk/guidance/ta477 [1604-2018]

Editor's note: Replies to questions raised by reviewers were incorporated into the text of the paper, so there is no Discussion with Reviewers section.

The Scientific Editor responsible for this paper was Martin Stoddart. 